\title{
Sorption of inorganic radiocarbon on iron oxides
}

\section{Lempinen, Janne}

2018-05

Lempinen , J , Muuri , E , Lusa , M \& Lehto , J 2018 , ' Sorption of inorganic radiocarbon on iron oxides ' , Journal of Radioanalytical and Nuclear Chemistry , vol. 316 , no. 2 , pp.

717-723 . https://doi.org/10.1007/s10967-018-5793-5

http://hdl.handle.net/10138/325770

https://doi.org/10.1007/s10967-018-5793-5

unspecified

acceptedVersion

Downloaded from Helda, University of Helsinki institutional repository.

This is an electronic reprint of the original article.

This reprint may differ from the original in pagination and typographic detail.

Please cite the original version. 


\section{Sorption of inorganic radiocarbon on iron oxides}

16 Radiocarbon, ${ }^{14} \mathrm{C}$, is assumed to be the most critical radionuclide, in addition to ${ }^{36} \mathrm{Cl}$ and

$17{ }^{129} \mathrm{I}$, with respect to prospective radiation doses to human resulting from the final disposal

18 of spent nuclear fuel in the future [1]. ${ }^{14} \mathrm{C}$ is a pure beta emitter and the maximum energy

19 of its beta particles is $156 \mathrm{keV}$ with a half-life of 5730 years. In Finland, the spent nuclear

20 fuel will be disposed of at the depth of about 400 meters in a bedrock repository. The

21 disposal will not include fuel reprocessing and thus the material to be disposed of consists

22 of the actual fuel material, i.e. irradiated uranium dioxide, as well as the Zircaloy 23 cladding and the metallic parts of the fuel assembly. In these, ${ }^{14} \mathrm{C}$ is produced when 
24 neutrons activate the nitrogen in the materials with the reaction ${ }^{14} \mathrm{~N}(\mathrm{n}, \mathrm{p}){ }^{14} \mathrm{C}$. It can be 25 found in the fuel material, Zircaloy cladding and steel structures in approximately equal 26 portions [2]. Furthermore, one tenth of radiocarbon is assumed to occur in the easily 27 soluble instant release fraction in fuel rod gaps and grain boundaries of the spent nuclear 28 fuel [3]. The chemical forms of ${ }^{14} \mathrm{C}$ in the fuel and metallic structures are still unclear but 29 it is assumed to occur as sparingly soluble carbide and elemental carbon [4-6]. Radiolysis 30 caused by the radiation from the nuclear fuel may, however, oxidize these sparingly 31 soluble species into more soluble species, for instance, carbon dioxide.

32 Very reducing conditions are prevailing at the Olkiluoto final disposal depth of 33 approximately 400 meters, which implies that the plausible oxidation state of carbon is 34 IV and that the chemical form of carbon is methane and partly higher hydrocarbons. The 35 study of Pitkänen and Partamies [7] has confirmed this when they determined the 36 chemical forms of dissolved carbon in the groundwater of Olkiluoto. While dissolved 37 carbon in the surface soil and in the upper parts of the bedrock is mainly as carbonate, its 38 concentration being up to $80 \mathrm{mg} / \mathrm{l}$, the methane concentrations in these layers are very 39 low at concentrations less than $1 \mathrm{~mL} / \mathrm{L}$. At the disposal depth the situation is vice versa as 40 the carbonate concentration is at a few $\mathrm{mg} / \mathrm{L}$ and that of methane a few hundred $\mathrm{mL} / \mathrm{L}$. It 41 is thus reasonable to assume that if any carbon is released from the fuel as carbon dioxide 42 it will be reduced to methane. Methane dissolved into water will not be retained on the 43 mineral surfaces but it can be transported in water conducting fractures closer to the 44 biosphere and, furthermore, be oxidized to carbonate at layers closer to ground surface. In 45 reality, very little is known about the behavior of ${ }^{14} \mathrm{C}$ in the bedrock and soil. As a result, 46 in the safety analysis it is conservatively presumed that ${ }^{14} \mathrm{C}$ is not retained at all in the 47 bedrock but is transported at the velocity of the groundwater flow.

48 Carbon occurs in the solid state in the bedrock either as calcite $\left(\mathrm{CaCO}_{3}\right)$ or graphite, 49 which both are common fracture minerals in the Olkiluoto bedrock together with pyrite 50 and clay minerals, such as kaolinite and illite [8]. In addition, carbon may occur in the 51 bedrock as siderite $\left(\mathrm{FeCO}_{3}\right) .{ }^{14} \mathrm{C}$ can be retained as carbonate on calcite and siderite 52 through isotope exchange [9-10]. There is constant dissolution and precipitation at equal 53 rates of calcite in solubility equilibrium with groundwater and, thus, also ${ }^{14} \mathrm{C}$ as carbonate 
$54\left({ }^{14} \mathrm{CO}_{3}^{2-}\right)$ in equilibrium with calcite water system will precipitate as carbonate in the 55 system.

56 In addition to calcite and siderite, ${ }^{14} \mathrm{C}$ as carbonate can be retained on the surfaces of iron

57 oxide minerals, the surfaces of which are at least partly positive due to the protonation of

58 the hydroxyl groups [11]. The formation of a monodentate inner-sphere carbonate surface

59 complex has been suggested as a possible adsorption reaction of carbonate on goethite

60 based on ATR-FTIR studies [12-13] whereas bidentate complexation on hematite has

61 been claimed by Brechbühl et al. [14]. Protonation and the positive charge of the minerals

62 surfaces is highly $\mathrm{pH}$ dependent: the lower the $\mathrm{pH}$, the higher the positive charge. The

63 surface charge of iron oxides in groundwater in the typical $\mathrm{pH}$ range of 8-9 is mostly

64 neutral and thus sorption is presumably low.

65 The sorption of ${ }^{14} \mathrm{C}$ as carbonate in goethite, hematite and magnetite was studied here as a

66 function of carbon concentration. In addition, the effect of competing ions and $\mathrm{pH}$ was

67 investigated and the results were modelled with PhreeqC. The isoelectric points (IEP) and

68 the specific surface areas of the studied minerals was determined to support the

69 modelling of the results. The three iron oxides used in this study represent iron oxides at

70 various environmental redox conditions. Magnetite, $\mathrm{Fe}_{3} \mathrm{O}_{4}$, is most prevailing in non-

71 oxic conditions and composes of both di- and trivalent iron. The two other oxides,

72 goethite $\alpha-\mathrm{FeOOH}$ and especially hematite $\alpha-\mathrm{Fe}_{2} \mathrm{O}_{3}$, containing only trivalent iron, are

73 prevailing in more oxidizing conditions. These two latter are the most abundant iron 74 oxides in soils.

\section{$75 \quad$ Experimental}

$76 \quad$ Minerals

78 The mineral powders used in the batch sorption experiments were Alfa Aesar (Ward Hill, 79 MA, USA) produced goethite ( $\alpha$-phase, Powder), hematite ( $\alpha$-phase, nanopowder, $98 \%$ 80 metals basis, 30-50 nm APS Powder) and magnetite (98\% metals basis, 20-30 nm APS 
Journal of Radioanalytical and Nuclear Chemistry 2(2018)717-723

81 Powder). Specific surface areas were measured at the Chalmers University of

82 Technology, Sweden, with the Kr-BET method.

\section{Batch sorption experiments}

86 Batch sorption experiments were performed to determine the sorption isotherms for

87 carbonate and to study the effect of $\mathrm{pH}$ and ionic strength on the sorption. For sorption

88 isotherms, samples with various concentrations of $\mathrm{NaHCO}_{3}$ and $0.01 \mathrm{M}$ TRIS buffer

89 (tris(hydroxymehthyl)aminomethane) ( $\mathrm{pH}$ 8.2) were prepared and radiolabeled with 18.5

$90 \mathrm{kBq}$ of $\mathrm{NaH}^{14} \mathrm{CO}_{3}$. The minerals were added into these solutions as suspensions in MilliQ

91 water to achieve a sample volume of $20 \mathrm{~mL}$ (Milli-Q ${ }^{\circledR}$ system with Quantum ${ }^{\circledR}$ polishing

92 cartridge, Merck, Germany). The solid to liquid ratio was $5 \mathrm{~g} / \mathrm{L}$ and initial ${ }^{14} \mathrm{C}$ activity

93 concentration $925 \mathrm{~Bq} / \mathrm{mL}$. The samples were left to equilibrate under shaking for one

94 week in capped vials. Activity standard for the radioactivity measurement was prepared

95 by adding MilliQ water instead of the mineral-water suspension and background sample

96 by adding stable $\mathrm{NaHCO}_{3}$ without the tracer.

98 After the equilibration period, aliquots of the samples were ultracentrifuged and $0.5 \mathrm{~mL}$

99 subsamples of the supernatants were mixed with $1 \mathrm{~mL}$ of $0.1 \mathrm{M} \mathrm{NaOH}$ to prevent

100 degassing of $\mathrm{HCO}_{3}{ }^{-}$as $\mathrm{CO}_{2}$. Finally, $10 \mathrm{~mL}$ of OptiFluor LSC cocktail was added to each

101 sample and the samples were measured for ${ }^{14} \mathrm{C}$ with Hidex 300 SL liquid scintillation

102 spectrometer. The TDCR (triple-to-double coincidence ratio) was used as a counting 103 efficiency determination method of each sample.

104

105 The fraction of sorbed carbonate ions was calculated from the decrease in the activity 106 concentration of the solution assuming isotopic equilibrium between stable and 107 radioactive carbonate ions.

108 The Langmuir isotherm equation

109

$$
q=\frac{q_{0} K_{L^{c}}}{1+K_{L^{c}}}
$$


110 where $q$ is the sorbed amount (in mol/ $\mathrm{kg}$ mineral) and $c$ the carbonate ion concentration

111 in the solution was used to find the constants $q_{0}$ and $K_{L}$ that represent the maximum

112 sorption (mol/kg) and equilibrium constant for the sorption reaction, respectively. A non-

113 linear curve fit to the experimental $q$ over $c$ data using fitting equation (1) was performed

114 using OriginPro 8.6 software. Moreover, the surface site density was calculated from the

115 maximum sorption and specific surface area of the minerals.

116 In order to study the effect of $\mathrm{pH}$ and ionic strength on the sorption, sets of samples were

117 prepared as described above at three different ionic strengths $(0,0.01$ and $0.1 \mathrm{M})$ using

$118 \mathrm{NaCl}$ as the background electrolyte and $\mathrm{HCl}$ and $\mathrm{NaOH}$ for $\mathrm{pH}$ adjustment. The $\mathrm{NaHCO}_{3}$

119 concentration in the samples was kept at $5 \cdot 10^{-5} \mathrm{M}$ and the initial ${ }^{14} \mathrm{C}$ activity

120 concentration at $925 \mathrm{~Bq} / \mathrm{mL}$. Also these samples were allowed to equilibrate for one

121 week, which after the samples were ultracentrifuged and supernatant activity was

122 measured as described above.

123 From the activity measurement results, the distribution coefficient $K_{d}$ was calculated 124 using equation

$125 \quad K_{d}=\frac{A_{0}-A}{A} \times \frac{V}{m}$

126 where $A_{0}$ and $A$ are the initial and final activity concentrations (Bq) of the solution,

127 respectively, and $V$ and $m$ the sample volume (L) and mass (kg), respectively.

128 The $\mathrm{pH}$ values of the remaining suspensions were measured using a glass electrode. For

129 all the sorption isotherm samples, the $\mathrm{pH}$ remained constant at $8.2 \pm 0.2$. For the $\mathrm{pH}$

130 dependent samples, the samples having a $\mathrm{pH}$ value lower than 6.5 were excluded from

131 the results as inorganic radiocarbon may gas out as $\mathrm{CO}_{2}$ at low $\mathrm{pH}$.

132 As only very low sorption of carbonate on magnetite was observed in studied conditions

133 it is not discussed in detail in the further treatment.

\section{Zeta potential measurements}

137 The zeta potentials of goethite and hematite were measured using a Malvern Zetasizer 138 instrument. For these measurements $0.5 \mathrm{~g} / \mathrm{L}$ suspensions of each mineral was prepared in 139 MilliQ water, $0.01 \mathrm{M} \mathrm{NaCl}$ or $0.1 \mathrm{M} \mathrm{NaCl}$. $\mathrm{pH}$ of the suspensions was adjusted using 
$1400.01 \mathrm{M} \mathrm{HCl}$ or $\mathrm{NaOH}$. The solutions were left to equilibrate in capped polyethylene vials

141 for one week before the measurement of zeta potential. Due to what is considered random

142 noise in the zeta potential data, smoothed curves as 5-point moving average were

143 produced using OriginPro 8.6 software in order to find the isoelectric points (IEP) of the 144 minerals.

\section{Geochemical modelling}

148 The sorption of carbonate on goethite and hematite was modelled with PhreeqC 149 Interactive using a generalized double-layer surface complexation model (Dzombak \&

150 Morel, 1990) and the phreeqc.dat database. IEP values were obtained from Zeta potential 151 measurements and sorption site densities from Langmuir fitting of the carbonate sorption 152 isotherms. Based on the works of Appello et al. [16], Brechtbühl et al. [14], Villalobos et 153 al. [13] and van Geen et al. [11] on carbonate sorption on hematite and goethite the 154 sorption was considered to consist of two reactions:

$$
\begin{aligned}
& \mathrm{Fe}-\mathrm{OH}+\mathrm{CO}_{3}{ }^{2-}+\mathrm{H}^{+} \leftrightarrow \mathrm{Fe}-\mathrm{O}-\mathrm{CO}_{2}^{-}+\mathrm{H}_{2} \mathrm{O} \\
& \mathrm{Fe}-\mathrm{OH}+\mathrm{CO}_{3}{ }^{2-}+2 \mathrm{H}^{+} \leftrightarrow \mathrm{Fe}-\mathrm{O}-\mathrm{CO}_{2} \mathrm{H}+\mathrm{H}_{2} \mathrm{O}
\end{aligned}
$$

157 resulting from ligand exchange reactions of carbonate and bicarbonate ions.

158 In the model, the oxide/water interface is presumed to be composed of two layers of 159 charge: a surface layer and a diffuse layer of counterions in solutions. As a result, all 160 specifically adsorbed ions are assigned to the surface layer, while all non-specifically 161 sorbed counterions are assigned to the diffuse layer [11,17]. The charge of an oxide 162 surface is determined by proton transfer reactions and surface coordination reactions. The 163 dependence of surface charge on $\mathrm{pH}$ is attributed to protonation and deprotonation 164 reactions of the surface sites:

$$
\begin{aligned}
& \mathrm{Fe}-\mathrm{OH}+\mathrm{H}^{+} \leftrightarrow \mathrm{Fe}-\mathrm{OH}_{2}^{+} \\
& \mathrm{Fe}-\mathrm{OH} \leftrightarrow \mathrm{Fe}-\mathrm{O}^{-}+\mathrm{H}^{+}
\end{aligned}
$$

167 Apparent equilibrium constants for these surface species for different minerals can be

168 calculated from zeta potential data as the reactions (5) and (6) are affected by the variable 169 charge of the oxide surface. 
Journal of Radioanalytical and Nuclear Chemistry 2(2018)717-723

170 Using IEP values and sorption site densities, the surface complexation constants of the 171 reactions (3) and (4) were modelled to best fit with the carbonate isotherm data.

172 The $\mathrm{CO}_{2}$ saturation indices for the solutions in sorption isotherm samples were checked 173 with PhreeqC modelling to fall under -3.42 (corresponding to atmospheric $\mathrm{CO}_{2}$ 174 concentration of $380 \mathrm{ppm}$ ). Sorption isotherm data exceeding this SI value was excluded 175 from further calculations because degassing of carbon dioxide from these solutions could 176 not be ruled out.

\section{Results and discussion}

The zeta potential of hematite and goethite at three ionic strengths as a function of $\mathrm{pH}$ are 181 shown in Fig. 1. The data suffers from irregularities that are considered as noise and the 182 curves show the smoothed data that was used to find the isoelectric point of the minerals. 183 For goethite, the ionic strength had no significant effect on the isoelectric point which 184 was found to fall between $\mathrm{pH}$ values 9.1 and 9.3. Here the IEP of goethite is taken as 9.2 $185 \pm 0.1$. For hematite, the IEP varied between 6.5 and 6.9 , and thus the value $6.7 \pm 0.2$ was 186 selected for the IEP of hematite. The IEP values determined were used in the modelling 187 of the sorption results. The reported IEP values of iron oxides vary considerably from one 188 product to another, in the range 7.4-9.4 for goethite and 7.0-9.3 for hematite [15]. Our 189 value for hematite lies in the upper end of the range while that of goethite falls below the 190 reported range. Based on the observed values one would assume that hematite would be 191 the most efficient in anion sorption due to its positive surface up to $\mathrm{pH} 9.3$ while goethite 192 would hardly take any anions at relevant groundwater $\mathrm{pH}$ values between 7 and 9. This 193 will be discussed later. The reported IEP value for magnetite lies in the range 6.0-6.8

194 being logical with our observation of no carbonate sorption taking place [15]. The 195 measured specific surface area values were $15.8 \pm 0.1 \mathrm{~g} / \mathrm{m}^{2}, 113 \pm 0.2 \mathrm{~g} / \mathrm{m}^{2}$ and $41.0 \pm$ $1960.1 \mathrm{~g} / \mathrm{m}^{2}$ for goethite, hematite and magnetite, respectively. 

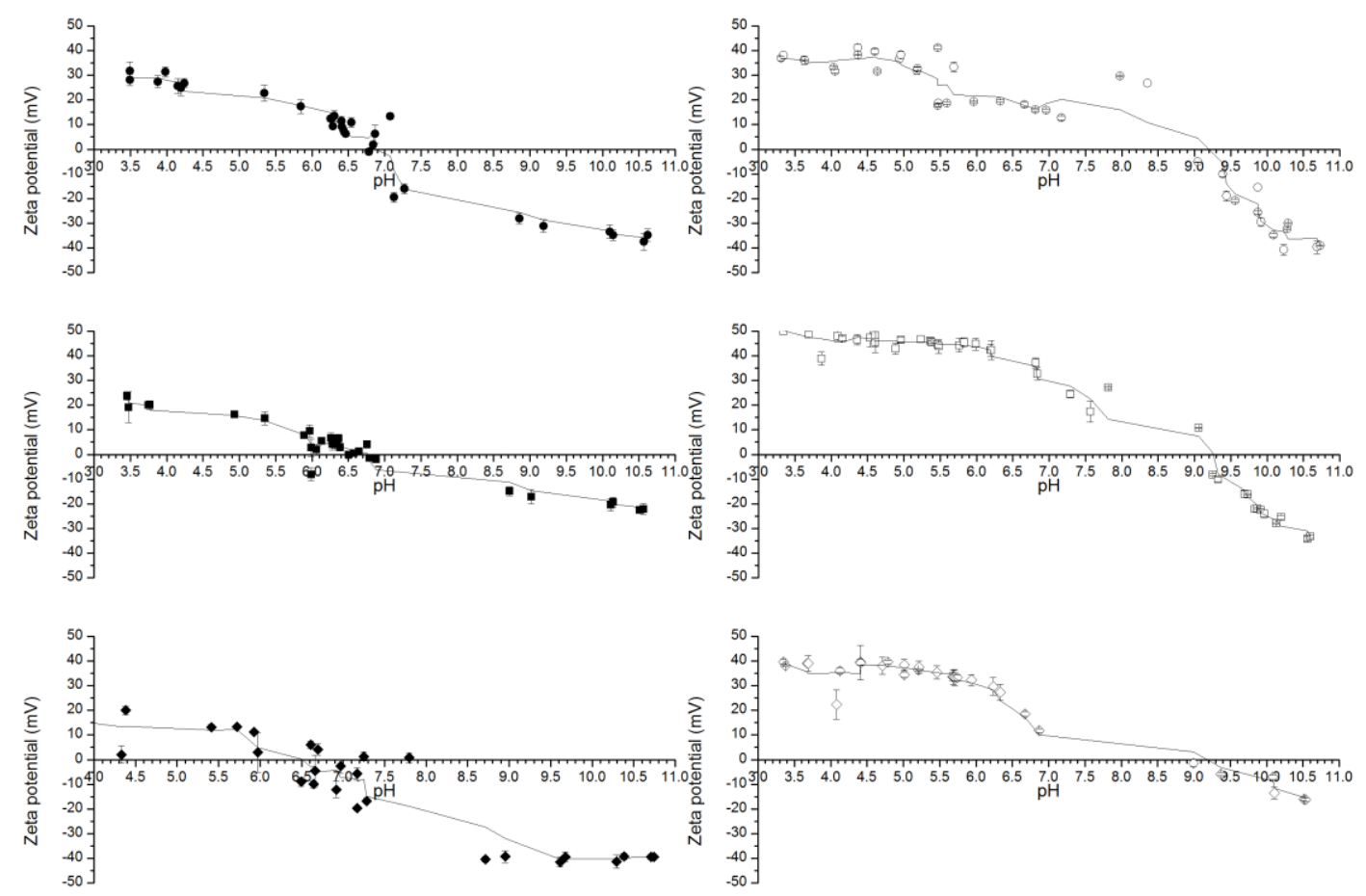

Fig. 1 The zeta potentials of hematite (right-hand side) and goethite (left-hand side) as a function of $\mathrm{pH}$. Hematite in MilliQ water (,), $0.01 \mathrm{M} \mathrm{NaCl}(!)$ and $0.1 \mathrm{M} \mathrm{NaCl}(\Lambda)$ and goethite in MilliQ water $(-), 0.01 \mathrm{M} \mathrm{NaCl}(\forall)$ and $0.1 \mathrm{M} \mathrm{NaCl}(\mathrm{M})$. The smoothed curves show the 5-point moving average of the data.

The carbonate sorption isotherms for goethite and hematite were rather similar (Fig. 2). The sorption of carbonate on magnetite was at a very low level of about $1 \mathrm{mmol} / \mathrm{kg}$ at maximum and thus magnetite is not further discussed. The measured carbonate sorption data of goethite and hematite could be reproduced well with the Langmuir equation as is

210 seen in Figure 2 on the right. The constants $q_{0}$ and $K_{L}$ are given in Table 2 along with the 
211 specific surface areas and calculated sorption site densities. For goethite, the $\mathrm{pH} 8.2$ in 212 the sorption isotherm samples was less than the IEP 9.2 and the surface of the mineral 213 was thus cationic which favors the sorption of carbonate ions by anion exchange or 214 surface complexation. However, for hematite the IEP of 6.7 was lower than that in the 215 batch experiments, which implies an anionic surface for hematite and thus anion 216 exchange is not a feasible sorption mechanism.
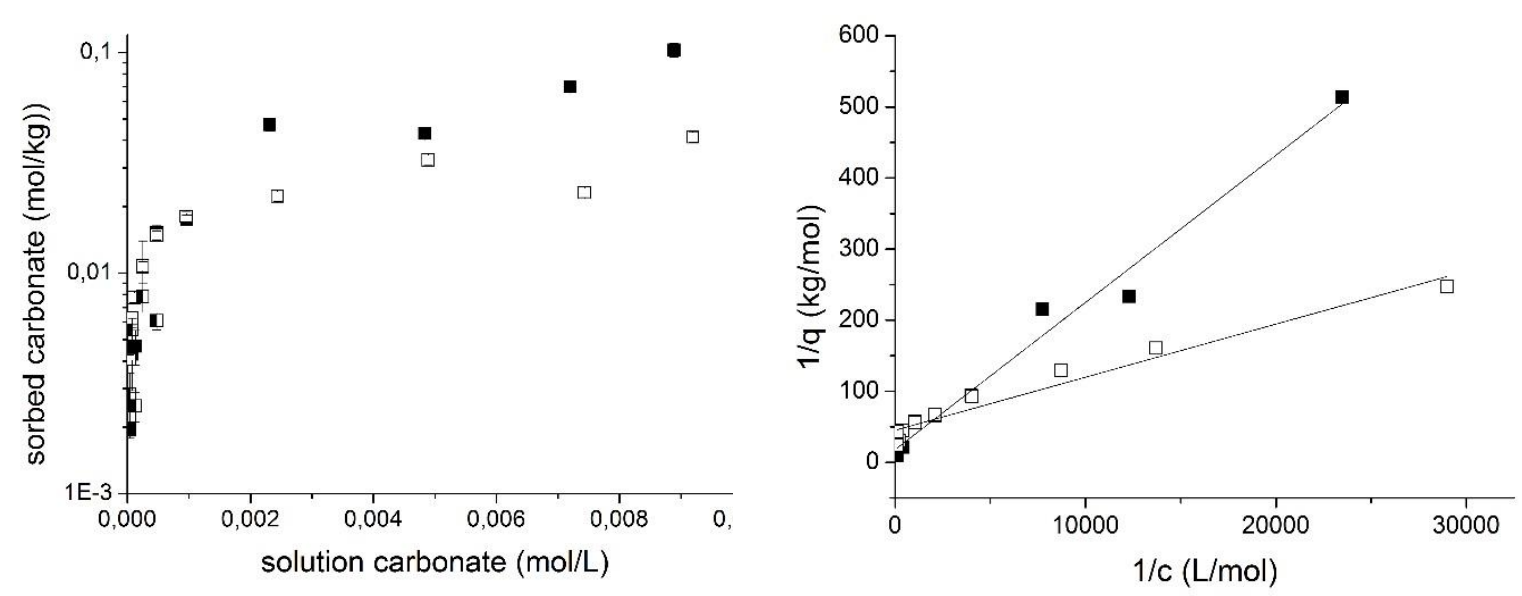

217 Fig. 2 Sorption isotherms of carbonate ions on hematite (!) and goethite $(\forall)$ at pH $8.2 \pm$ 0.2 (left) and Right the Langmuir fittings of the results (right).

Table 2. The maximum sorption $q_{0}$, sorption equilibrium constant $K_{L}$, the adjusted $R^{2}$ of 221 the non-linear curve fit, the specific surface area s and sorption site density $d$ for the 222 sorption of carbonate ions on hematite and goethite.

\begin{tabular}{|l|l|l|l|l|l|}
\hline Mineral & $\begin{array}{l}\boldsymbol{q}_{\mathbf{0}} \\
(\mathbf{m o l} / \mathbf{k g})\end{array}$ & $\begin{array}{l}\mathbf{K}_{\mathbf{L}} \\
(\mathbf{L} / \mathbf{m o l})\end{array}$ & $\begin{array}{l}\text { Adj. } \\
\mathbf{R}^{\mathbf{2}}\end{array}$ & $\mathbf{s}\left(\mathbf{m}^{\mathbf{2}} / \mathbf{g}\right)$ & $\mathbf{d}$ \\
\hline Hematite & 0.056 & 660 & 0.985 & $113 \pm 0.5$ & 0.30 \\
\hline Goethite & 0.022 & 6010 & 0.959 & $15.8 \pm 0.1$ & 0.84 \\
\hline
\end{tabular}

223

$224 \quad$ Effect of ionic strength and $\mathrm{pH}$ 
226 At $\mathrm{pH}$ 6.5-7.0 the distribution coefficient of carbonate on hematite and goethite were at 227 the same level, at $100-300 \mathrm{~mL} / \mathrm{g}$ (Fig. 3). At higher $\mathrm{pH}$ values $\mathrm{K}_{\mathrm{d}}$ decreased 228 systematically, for hematite more drastically, being below $10 \mathrm{~mL} / \mathrm{g}$ already at $\mathrm{pH} 8$ while 229 for goethite the $\mathrm{K}_{\mathrm{d}}$ remained above this value up to $\mathrm{pH}$ 10.5. This behavior is logical 230 considering the IEPs of the minerals, 6.7 for hematite and 9.2 for goethite. The declining 231 trend was as expected because the positive charge of the mineral surfaces decreases as the $232 \mathrm{pH}$ increases and thus the sorption of carbonate decreases. Furthermore, as the $\mathrm{pH}$ 233 decreases the speciation of carbon changes from carbonate $\left(\mathrm{CO}_{3}{ }^{2-}\right)$ to bicarbonate $\left(\mathrm{HCO}_{3}{ }^{-}\right.$

234 ) and finally to carbon dioxide $\left(\mathrm{CO}_{2}\right)$ (Fig. 4). This decreases the negative charge of the 235 sorbing species and, consequently, decreases the sorption on negatively charged mineral 236 surfaces. Thus, as the $\mathrm{pH}$ decreases there are two factors acting to opposite directions: 237 increasing protonation favors sorption while protonation of the carbonate ions diminishes 238 it.

239 The ionic strength had only a slight decreasing effect on the distribution coefficient, 240 which is in line with the fact that sorption mechanism is inner-sphere complexation. The 241 decreasing effect caused by the ionic strength can be due to the saturation of sorption 242 sites caused by the interactions of chloride ions on the plane typically occupied by 243 electrolyte outer-sphere complexes. The negative charge of carbonate complex extending 244 onto the diffuse layer is highly influenced by the electrostatic field created by the 245 adsorption of electrolyte anions, such as chloride ions, on this plane [13]. Therefore, an 246 increase in ionic strength causes an increase of negative charge on this plane and thus a 247 decrease in carbonate adsorption. Furthermore, in higher $\mathrm{NaCl}$ concentrations sodium 248 complexes play a more significant role in the speciation of carbon and, at higher $\mathrm{pH}$ 249 values $\mathrm{NaCO}_{3}{ }^{-}$is a dominating species together with $\mathrm{CO}_{3}{ }^{2-}$ (Fig. 4). 

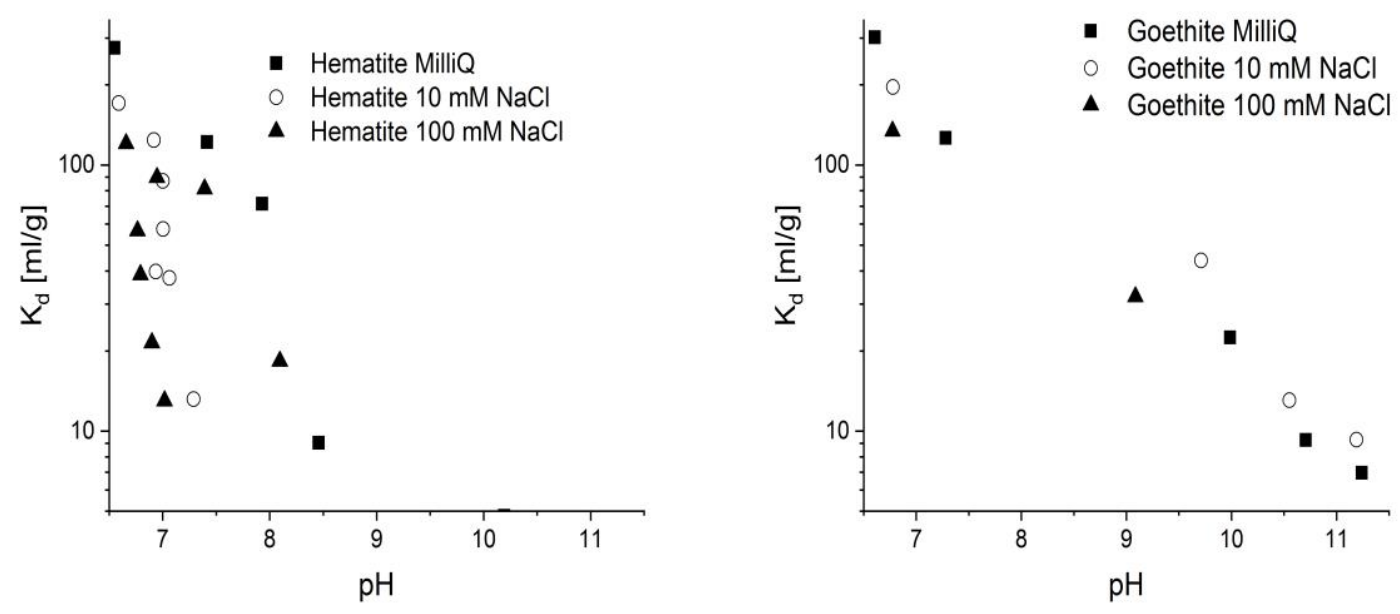

250 Fig. 3 Distribution coefficients of carbonate on hematite (left) and goethite (right) as a function of $\mathrm{pH}$ in MilliQ, $10 \mathrm{mM} \mathrm{NaCl}$ and $100 \mathrm{mM} \mathrm{NaCl}$ solutions.
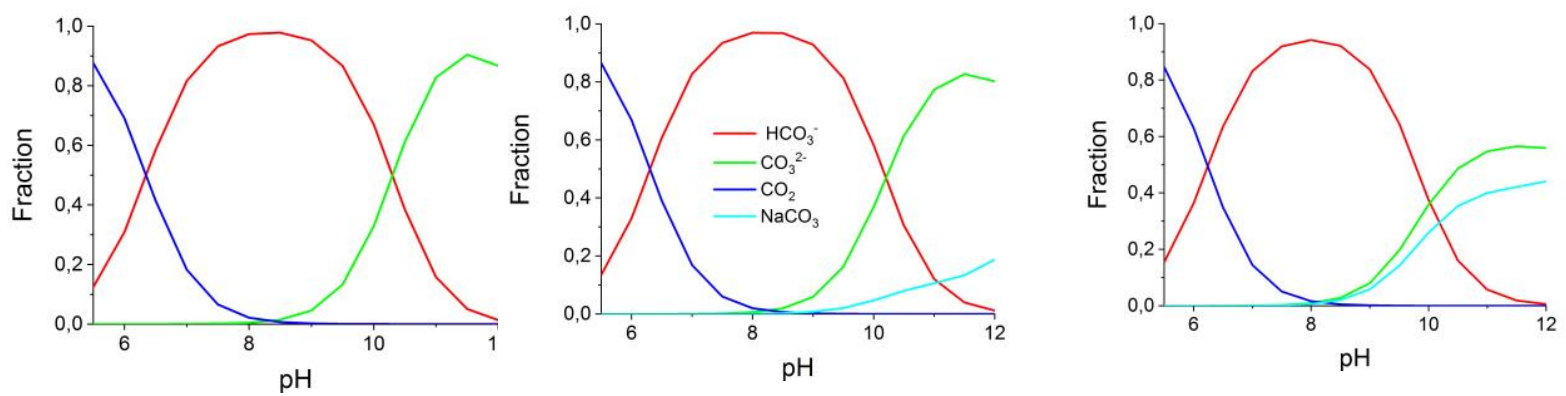

Fig. 4 Aqueous speciation of carbon. Left: MilliQ, Middle: $0.01 \mathrm{mM} \mathrm{NaCl,} \mathrm{Right:} 0.1$ $\mathrm{mM} \mathrm{NaCl}$ modelled with PhreeqC. Thermodynamic data from phreeqc.dat was used.

\section{Geochemical modelling}

259 The sorption results were modelled with PhreeqC using a generalized double-layer 260 surface complexation model using IEP values obtained from Zeta potential measurements 261 and the sorption sites densities obtained from specific surface area measurements and the 262 Langmuir isotherms. Surface complexation constants for the two reactions described in 263 Equations 3 and 4 were obtained from the best fit with experimental isotherm data (Table 264 1). As a starting point in modelling of surface complexation constants the values reported 
265 by Appelo et al. [16] and Brechbühl et al. [14] were used. The model was able to 266 reproduce well the $\mathrm{pH}$ dependent sorption results of carbonate on goethite, but 267 underestimated the concentration dependent results (Fig 5). The sorption site density 0.84 268 sites $/ \mathrm{nm}^{2}$ used in the model was considerably smaller than 2.31 sites $/ \mathrm{nm}^{2}$ used by Van 269 Geen et al. [11] and by Dzombak and Morel [17], which may explain the low modelled 270 sorption compared to experimentally observed one. However, the fitting of the $\mathrm{pH}$ 271 dependent results would suffer from increasing the sorption site density. The surface 272 complexation constants obtained from the fitting (12.36 and 20.12) were close to the 273 values (12.78 and 20.37) obtained by Appelo et al. [16] in a similar study.

275 Table 1. Surface complexation constants for carbonate sorption on goethite and hematite 276 used in this study.

Surface complexation constants

$\log K$

Surface acid-base reactions on goethite

Hfo_wOH $=$ Hfo_wOH 0

$\mathrm{Hfo} \_\mathrm{wOH}+\mathrm{H}^{+}=\mathrm{Hfo} \_\mathrm{wOH}_{2}{ }^{+}$

Surface acid-base reactions on hematite

Hfo_wOH $=$ Hfo_wOH

Hfo_wOH $+\mathrm{H}^{+}=\mathrm{Hfo} \_\mathrm{wOH}_{2}{ }^{+}$

Carbonate sorption on goethite

$\mathrm{Hfo} \_\mathrm{wOH}+\mathrm{CO}_{3}{ }^{2-}+\mathrm{H}^{+}=\mathrm{Hfo}_{-} \mathrm{wCO}_{3}{ }^{-}+\mathrm{H}_{2} \mathrm{O}$

$\mathrm{Hfo} \_\mathrm{wOH}+\mathrm{CO}_{3}{ }^{2-}+2 \mathrm{H}^{+}=\mathrm{Hfo}_{-} \mathrm{wHCO}_{3}+\mathrm{H}_{2} \mathrm{O}$

Carbonate sorption on hematite

$\mathrm{Hfo} \_\mathrm{wOH}+\mathrm{CO}_{3}{ }^{2-}+\mathrm{H}^{+}=\mathrm{Hfo}_{-} \mathrm{wCO}_{3}{ }^{-}+\mathrm{H}_{2} \mathrm{O}$

$\mathrm{Hfo} \_\mathrm{wOH}+\mathrm{CO}_{3}{ }^{2-}+2 \mathrm{H}^{+}=\mathrm{Hfo}_{-} \mathrm{wHCO}_{3}+\mathrm{H}_{2} \mathrm{O}$ 

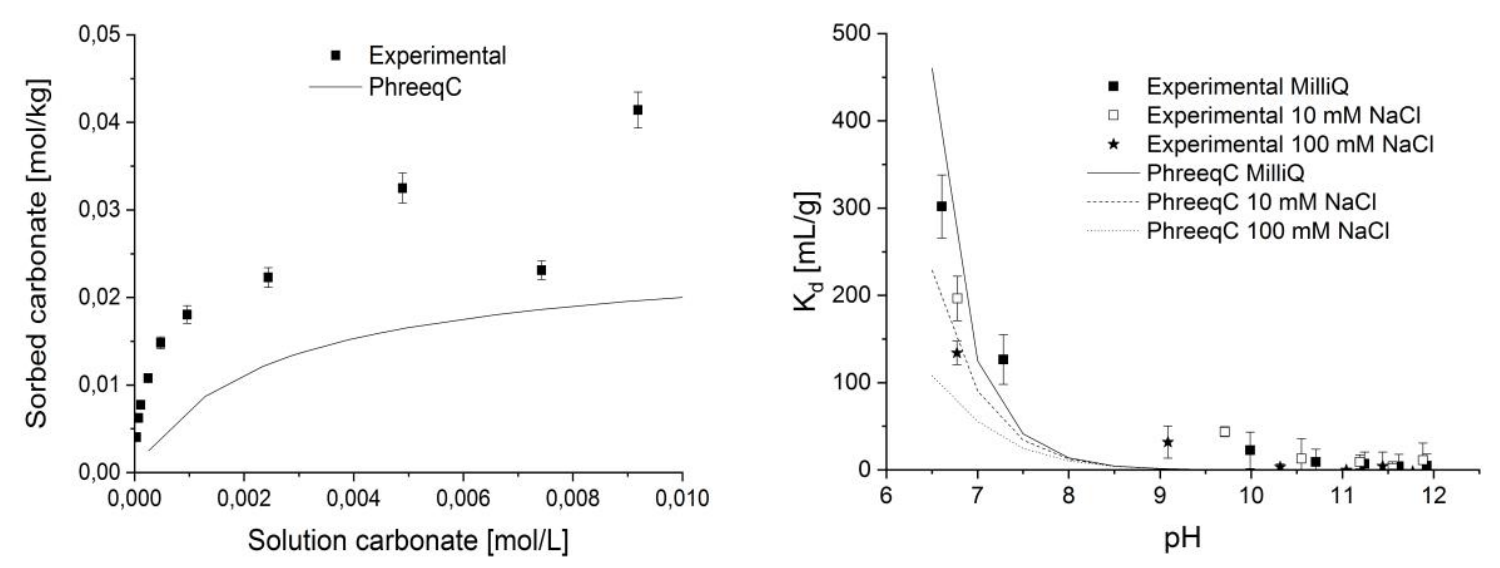

Fig. 5 The modelled sorption isotherms of carbonate on goethite.

282 The generalized double-layer surface complexation model reproduced the sorption results 283 of carbonate on hematite rather adequately (Fig 6). The surface complexation constants 284 obtained from the fitting (10.92 and 22.94) were the same as the values (10.92 and 21.94) 285 obtained by Brechbühl et al. [14] in a similar study while the sorption site density used in 286 this study 0.30 sites $/ \mathrm{nm}^{2}$ was considerably smaller than 12 sites $/ \mathrm{nm}^{2}$ used by Brechbühl et 287 al. [14].
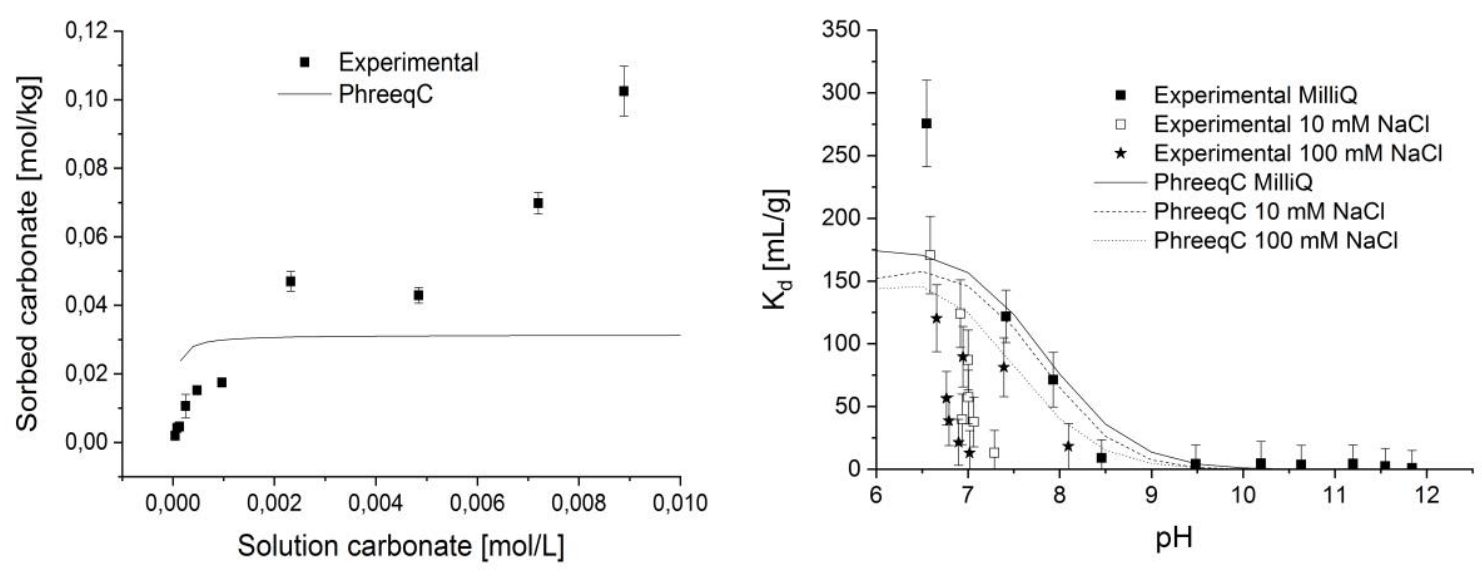

Fig. 6 The modelled sorption isotherms of carbonate on hematite. 


\section{Conclusions}

292 Carbonate was found to be considerably sorbed on goethite and hematite, but the sorption 293 on magnetite was negligible in all studied conditions. Sorption on goethite and hematite

294 was largest in the neutral $\mathrm{pH}$-range and it decreased with increasing $\mathrm{pH}$. This is caused by 295 the decreasing positive charge of the mineral surface as the $\mathrm{pH}$ increases. As $\mathrm{pH}$ 296 decreases the speciation of carbon changes from carbonate to bicarbonate and finally to 297 carbon dioxide decreasing the sorption, as the bicarbonate is less preferred compared to 298 carbonate. Carbonate sorption was also observed to slightly decrease with increasing 299 ionic strength, which can be due to the saturation of sorption sites caused by the 300 interactions of chloride ions on the plane typically occupied by electrolyte outer-sphere 301 complexes. The batch sorption results were modelled with the generalized double-layer 302 surface complexation model and the model was able to reproduce rather well the 303 experimental sorption results.

304 Considering the long-term consequences of the final disposal of spent nuclear fuel, we 305 may conclude that radiocarbon is not completely non-sorbing as presently is assumed in 306 conservative safety analyses. In addition to isotopic exchange reaction of carbonate with 307 calcite the sorption on iron oxides is a retarding process preventing rapid migration of 308 radiocarbon into the biosphere.

\section{$309 \quad$ Acknowledgements}

310 The research leading to these results received funding from the Finnish Research 311 Program on Nuclear Waste Management KYT2018.

\section{$312 \quad$ References}

313 1. Hjerpe T, Ikonen ATK, Broed R (2009) Biosphere assessment report 2009, Posiva 314 Oy, Posiva Report 2010-03. 
2. Posiva. (2013) Safety Case for the Disposal of Spent Nuclear Fuel at Olkiluoto Models and Data for the Repository System 2012. Posiva Oy, Posiva Report 2013-01.

3. Johnson L, Poinssot C, Ferry C, Lovera P (2004) Estimates of the Instant Release Fraction for $\mathrm{UO}_{2}$ and MOX fuel at $\mathrm{t}=0$. NAGRA Technical Report 04-08.

4. Limer LMC, Smith K, Albrecht A, Marang L, Norris S, Smith GM, Thorne MC and Xu S (2012) C-14 Long-Term Dose Assessment: Data Review, Scenario Development, and Model Comparison. Strålsäkerhetsmyndigheten, 2012:47.

5. Deng B, Campbell TJ, Burris TR. (1997) Hydrocarbon Formation in Metallic Iron/water Systems. Environ Sci Technol 31: 1185-1190.

6. Kaneko S, Tanabe H, Sasoh M, Takahashi R, Shibano T, Tateyama S (2003) A Study on the Chemical Forms and Migration Behavior of Carbon-14 Leached from the Simulated Hull Waste in the Underground Condition. Mat Res Soc Symp Proc, Vol. 757: 621-626.

7. Pitkänen P, Partamies S (2007), Origin and Implications of Dissolved Gases in Groundwater at Olkiluoto, Posiva Oy, Posiva Report 2007-04.

8. Aaltonen I, Engström J, Front K, Gehör S, Kosunen P, Kärki A, Mattila J, Paananen M, Paulamäki S. (2016) Geology of Olkiluoto. Posiva Oy, Posiva Report 2016-16.

9. Gonfiantini R, Zuppi GM (2003) Carbon Isotope Exchange Rate of DIC in Karst Groundwater. Chem Geology 197: 319-336.

10. Lempinen J, Lehto J (2016) Rate of Radiocarbon Retention onto Calcite by Isotope Exchange. Radiochim Acta 104(9): 663-671.

11. Van Geen A, Robertson AP, Leckie JO (1994) Complexation of Carbonate Species at the Goethite Surface: Implications for Adsorption of Metal Ions in Natural Waters. Geochim Cosmochim Acta 58: 2073-2086.

344 13. Villalobos M, Leckie JO (2001) Surface Complexation Modeling and FTIR Study

12. Wijnja H, Schulthess CP (2001) Carbonate Adsorption Mechanism on Goethite Studied with ATR-FTIR, DRIFT, and Proton Coadsorption Measurements. Soil Sci Soc Am J 65: 324-330. of Carbonate Adsorption to goethite. J Colloid Int Sci 235: 15-32. 
14. Brechbühl Y, Christl I, Elzinga EJ, Kretzschmar R (2012) Competetive Sorption of Carbonate and Arsenic to Hematite: Combined ATR-FTIR and Batch Experiments, J Colloid Int Sci 377: 313-321.

350 16. Appelo CAJ, Van Der Weiden MJJ, Tournassat C, Charlet L (2002) Surface Complexation of Ferrous Iron and Carbonate on Ferrihydrite and the Mobilization of Arsenic. Environ Sci Technol 36: 3096-3103.

353 17. Dzombak D.A and Morel F.M.M. (1990) Surface Complexation Modelling: Hydrous Ferric Oxide. John Wiley \& Sons, Inc. 